\title{
REDESENHANDO
}

\section{A PRÁTICA DOCENTE}

uma experiência tecida

no contexto de

\section{distanciamento social}

\author{
REDESIGNING TEACHING PRACTICE \\ an experience woven in the context of social distance
}

\author{
Orquídea Maria de Souza Guimarães \\ http://orcid.org/oooo-ooo1-6360-6067 \\ UFPE, Doutora em Educação
}

\section{RESUMO}

O texto constitui uma reflexão sobre a prática docente durante a pandemia, contexto que exigiu a vivência do ensino remoto, com aulas síncronas e assíncronas. A análise considerou a avaliação realizada pelos/as estudantes da turma de Residência Multiprofissional em Saúde, da UfPE, através de formulário on-line. Percebemos que a organização da disciplina remota, a atuação docente e o resultado da aprendizagem são estruturantes para se planejar e vivenciar uma disciplina nesse formato. Assim, consideramos que o ensino remoto, no contexto de pandemia, vai muito além de planejar atividades adaptadas para o mundo on-line, pois requer (re)construir saberes, modificar a lógica de pensar as maneiras de mediar a relação entre estudantes e conhecimento, e, em especial, perceber-se docente como um/a constante aprendente.

Palavras-chave: Ensino remoto; Prática docente; Reflexão sobre a prática.

\section{ABSTRACT}

This text is a reflection on teaching practice during COVID-19 pandemic, in a context that required the experience of remote education, with synchronous and asynchronous classes. The analysis considered an evaluation carried out by students in the Multidisciplinary Residency in Health class, at UFPE, through an online form. We realized that the organization of remote classes, the teaching performance and the learning outcome in the discipline are structuring devices for planning and experiencing a discipline in this format. Thus, we consider that remote education, in the context of a pandemic, goes far beyond planning activities adapted to the online world, since it requires (re)building knowledge, modifying the logic of thinking the ways 
to mediate the relationship between students and knowledge, and, in particular, maintaining teacher's self-perception as that of a constant learner.

Keywords: Remote teaching; Teaching practice; Reflection on practice.

\section{UM NOVO CONTEXTO DE ENSINO}

O distanciamento social, decorrente da pandemia causada pelo novo coronavírus, interferiu no funcionamento de todos os âmbitos sociais, a exemplo da educação. O Ensino Superior, especificamente, tem sido objeto de questionamentos quanto ao seu funcionamento, no que se refere à adesão ou não ao ensino a distância ou remoto. Essas questões são acompanhadas de discussão sobre as condições de professores/as e estudantes para a realização de um ensino mediado pelas tecnologias digitais da informação e comunicação.

Em paralelo às implicações sociais e às desigualdades que se aprofundaram no contexto pandêmico, interferindo diretamente na vida cotidiana de cada um/a, muitos desafios foram postos à prática docente e discente, como o acesso aos equipamentos e ferramentas tecnológicas e à internet de qualidade, além da efetivação do ensino, com a alteração direta das concepções de tempo, espaço e forma de realização, sem que, para isso, houvesse preparo.

Em nosso caso, o desafio foi o de efetivar a disciplina de Metodologia de Ensino, no curso de Residência Multiprofissional em Saúde da UFPE, em nível de Especialização. Essa disciplina tem o intuito de pensar estruturantes do ensino no contexto da formação e da atuação no campo da saúde, com uma carga horária de 45h. Presencialmente, ela tem ocorrido através de momentos de diálogo, com estratégias metodológicas de fala e escuta permanentes, que precisaram ser repensadas na condição do distanciamento.

Os/as 37 residentes da turma do primeiro semestre estavam distribuídos em três hospitais públicos e envolvidos com o atendimento a pacientes da Covid-19, o que trazia implicações diretas para a organização de seus plantões, assim como para a demanda de trabalho.

Ao final da disciplina, os/as residentes realizaram uma avaliação, através de questionário on-line, e, a partir dela, procedemos à análise temática que nos permitiu a construção deste texto, apresentando a análise reflexiva da experiência docente, especificamente a prática docente no contexto do ensino remoto, a partir do olhar discente. 
O relato dessa experiência foi proposto aqui por representar a teorização sobre a prática docente, resultante de um processo sistematizador, consequência da pesquisa como constituinte da docência universitária, logo, do ensino. Consideramos que o registro sistemático e sistematizado das experiências profissionais pode contribuir para a (re)construção da prática, identificando-a para além do estudo sobre o conhecimento a ser ensinado. Isso porque a socialização da experiência profissional fortalece a reflexão coletiva sobre a prática docente, entendida como social, relacional, política, histórica, institucional e pedagógica.

Dito isso, objetivamos com este texto analisar a vivência de uma disciplina no contexto do ensino remoto, identificando e caracterizando as estratégias e encaminhamentos docentes necessários a um ensino remoto que vise à garantia da aprendizagem de todos/as. A análise é aqui apresentada em dois momentos, que abordam as discussões sobre a reflexão sobre a prática docente e sobre as categorias construídas, possibilitando uma aproximação do que foi a experiência vivenciada. Finalizamos apresentando considerações que indicam pistas para a continuidade da aprendizagem profissional iniciada.

\section{DESAFIOS E APRENDIZAGENS PARA O ENSINO NO CONTEXTO REMOTO}

O domínio do conhecimento profissional pelo/a professor/a é elemento fundante no reconhecimento da profissão socialmente. No contexto universitário, esse domínio, que se distancia da ideia de detenção de todo o saber, tem na atividade da pesquisa um princípio articulador dos saberes requeridos na docência. A pesquisa, assim, se caracteriza como intrínseca ao próprio trabalho, e a reflexão sobre a prática, como requisito essencial para essa realização. Dito de outra maneira, a pesquisa orienta o próprio saber-fazer do/a professor/a universitário/a e o olhar sobre sua própria prática.

Se considerarmos que a prática docente é social, relacional, situada política e historicamente, o contexto de pandemia provocou a necessidade de (re)pensá-la sob outras condições, tendo apresentado ao ensino presencial as demandas que o levariam a realizar-se de maneira remota. Nessa perspectiva, o ensino foi se desenhando a partir das produções, dinâmicas e experiências da modalidade do ensino a distância (EaD), em especial no que se refere ao uso de ferramentas tecnológicas e ao planejamento, ao acompanhamento e à avaliação do ensino e da aprendizagem. 
No entanto, o ensino remoto não é $\mathrm{EaD}$, e, em decorrência disso, o desenho envolveu a natureza presencial do curso, a proposição da disciplina para a formação específica, as limitações que o contexto de pandemia tem imposto à vida cotidiana, a mudança na forma de oferta do curso, sem que isso tenha sido pensado em seu projeto pedagógico, e a adaptação das formas de perceber e compreender o tempo e o espaço nesse novo formato de viver uma disciplina. E, como resultado, a prática docente foi redesenhada, em um movimento permanente entre seu rascunho e a versão finalizada.

Esse contexto, impensado até há pouco mais de um semestre, provocou a necessidade de mobilização de uma diversidade de saberes profissionais e o reconhecimento de nossa condição de seres inconclusos e, por isso, em permanente formação profissional (FREIRE, 2007). Além disso, põe em relevo o saber da experiência profissional em seu movimento de construção, frente a demandas geradas pelo contexto pandêmico, por ser este um saber que traduz e reformula os demais saberes, uma vez “[...] que o profissional desenvolve na ação através de questionamentos que este se faz diante de situações problemáticas com as quais ele deverá compor" (THERRIEN; LOIOLA, 2001, p. 155).

Para diversos autores/as (PIMENTA, 2002; TARDIF, 2000; THERRIEN, 1993; entre outros), uma vivência específica passa a ser construída e passa a direcionar ações docentes à medida que se repete. Isto é, ao ser construída e incorporada como um saber construído, será mobilizada pelos/as professores/as a cada situação em que for considerada necessária. A longa duração do distanciamento social e, em especial, do convívio acadêmico não presencial, permite que essa experiência profissional vá sendo consolidada e aprimorada através de um olhar crítico e reflexivo da prática. "De fato, aprender através de suas próprias experiências significa viver um momento particular, momento esse diferente de tudo o que se encontra habitualmente, sendo registrado como tal em nosso repertório de saberes" (GAUTHIER et al., 2006, p. 32-33).

Os desafios para a prática docente, a ser desenvolvida através do formato remoto, estavam postos, provocando a necessidade de novas aprendizagens, tendo como referência os saberes já construídos. Se, por um lado, perguntas sobre o que e para que ensinar podiam ser respondidas facilmente, o como ensinar passou a requerer uma (re)construção, considerando sua dimensão político-pedagógica, que, no contexto de distanciamento social vivido, passa a exigir práticas que assegurem, ainda mais, o compromisso democrático e humanizado com o ensino. 
Nesse sentido, é preciso considerar, ainda, que:

A educação em rede, pela sua natureza, é um processo que requer o envolvimento profundo dos diferentes atores que nela participam, quer na definição dos objetivos e percursos de aprendizagem da comunidade, quer também nas relações de proximidade construídas nas colaborações entre pares que sustentam os processos de inovação e criação do novo conhecimento (MOREIRA; HENRIQUES; BARROS, 2020, p. 355).

Essas considerações destacam que a natureza relacional do processo de ensino e aprendizagem permanece necessária quando se pensa no ensino na condição remota, e é através dessa relação que se constrói o novo e se inova, inclusive, o existente.

Retomemos aqui a necessidade de repensar as formas de perceber e planejar o tempo e o espaço nesse novo formato de viver uma disciplina. $\mathrm{O}$ ensino remoto privilegia atividades assíncronas (acesso às aulas em momentos distintos) em relação às síncronas (professor/a e estudantes na aula simultaneamente), reconfigurando o tempo proposto, que passa a ser vivido "separadamente" entre docente e turma.

A proposição das estratégias de ensino nesse formato se assemelha às das metodologias ativas, no que tange ao protagonismo do/a estudante que construirá sua aprendizagem de maneira mais autônoma (FIlATro; CAVAlCANTI, 2018). Em decorrência disso, o processo do ensino exigirá a proposição de orientações mais minuciosas, detalhadas, para que cada estudante possa vivenciar cada proposta como se o/a professor/a estivesse ao seu lado, como ocorre nas aulas do ensino presencial.

Outra implicação decorrente dessa diferença de tempo relaciona com a forma de acompanhamento das produções da turma, solicitando do/a docente a realização de intervenções que colaborem com o desenvolvimento da aprendizagem de cada estudante. Além de se pensar em instrumentos específicos que permitam apresentar o que cada estudante e a turma estão aprendendo, a forma de registro das intervenções também sofre alterações, de modo a permitir aos/às estudantes a clareza sobre o que foi considerado pelo/a professor/a. $\mathrm{O}$ tempo mais breve também exige cuidado com as intervenções docentes, para assegurar que ajudarão na aprendizagem dos discentes em seu percurso ao longo da disciplina.

No que diz respeito ao espaço, temos inicialmente o deslocamento da sala de aula de um ambiente físico, com horário determinado de funcionamento, para um ambiente virtual que pode estar ativo permanentemente e ter acesso livre. Se a aula está 
vinculada à compreensão de ser um ambiente de aprendizagem, independentemente do espaço em que ocorre (MASETTO, 2003), essa mudança pode trazer implicações mais operacionais e menos conceituais. Por outro lado, se a sala é compreendida como espaço para que ocorra a aula, os desafios podem se acentuar. De acordo com Moreira, Henriques e Barros (2020):

Uma sala de aula online não é um repositório de conteúdos digitais, é um espaço ativo e dinâmico onde os estudantes recebem informações sobre as atividades online que devem realizar, dentro e fora da plataforma, individualmente ou em grupo, exatamente como num ambiente de sala de aula física (MOREIRA; HENRIQUES; BARROS, 2020, p. 357)

Ou seja, a aula no espaço virtual não é um lugar físico, é um espaço destinado à orientação, organização do material, proposição das atividades, espaço de interações, mesmo que sejam realizadas em tempos distintos, mas que diretamente se relacionam.

Considerando o que até aqui foi exposto, sobre os movimentos de mudança na prática docente, provocados pelas implicações sociais da pandemia, seja através das demandas profissionais, seja em função das demandas da vida cotidiana, continuamos a discussão a partir do diálogo com os/as estudantes, a partir das suas percepções sobre a construção de uma disciplina presencial para ser vivida de maneira remota.

\section{A PRÁTICA DOCENTE E SEU (RE)DESENHO NO CONTEXTO REMOTO}

A disciplina objeto desta reflexão foi organizada para ocorrer em nove encontros, de cinco horas, quando poderiam ocorrer atividades síncronas e assíncronas. A programação proposta foi de três encontros síncronos, através do aplicativo de videoconferência Google Meet, distribuídos no início, na metade e ao final da disciplina.

As aulas assíncronas foram planejadas com a apresentação de um plano de aula, de um texto como referência para leitura, de slides sobre a temática e de uma atividade a ser construída individualmente, ou em grupo, ou ainda em duplas ou trios. A partir das atividades realizadas, intervenções eram feitas em cada uma, ou de maneira coletiva.

No último encontro, solicitamos à turma a realização de uma avaliação individual sobre o desenvolvimento da disciplina, através do preenchimento de um formulário do Google Forms, sem identificação (por isso, ao apresentarmos as respostas, faremos a flexão nos dois gêneros gramaticais). As questões envolveram 
aspectos relacionados ao conhecimento abordado na disciplina, às estratégias utilizadas e ao acompanhamento docente.

A análise realizada identificou que a organização da disciplina, a atuação docente e o resultado da aprendizagem na disciplina foram entendidos como aspectos importantes para serem planejados, acompanhados e avaliados no contexto do ensino remoto. Essas categorias serão abordadas em separado, mas aconteceram de maneira articulada e dialogada.

\section{A ORGANIZAÇÃO DA DISCIPLINA}

O Google Sala de Aula foi selecionado como lugar para orientação, organização das aulas, compartilhamento das atividades e produções dos/as estudantes. Inicialmente, seu uso parecia ser fácil, como se existisse quase um conhecimento tácito sobre a sua utilização, gerando uma certa sensação de conforto.

Para iniciar o contato com os alunos, uma mensagem de boas-vindas sinalizava o começo dos trabalhos, propondo a vivência de uma disciplina dialogada, como mostra a figura a seguir:

\section{Figura 1. Introdução à sala de aula}

$\equiv$ Metodologia do Ensino-COREMU

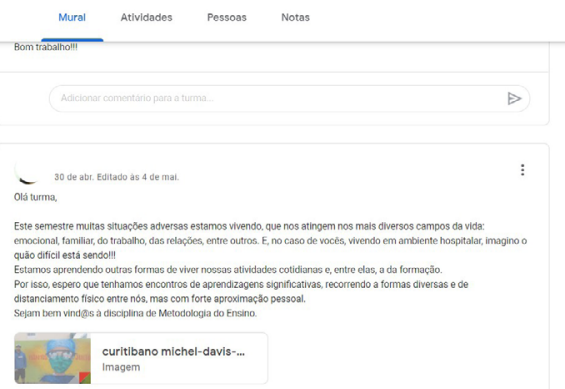

Fonte: Imagem do programa Google Sala de Aula. Produção da autora, 2020.

Apesar de a saudação sinalizar uma relação aproximada entre a professora e a turma, não houve qualquer orientação sobre como ocorreria a disciplina, sobre a forma de organização, nem mesmo sobre como a comunicação seria realizada. Além disso, o espaço para a conversa inicial e as apresentações individuais, que colaboram com a construção da identidade da turma (docente e discentes), existiu apenas no primeiro encontro síncrono, em função da dificuldade de alguns/as residentes, o que terminou retardando essa construção. Essas ausências geraram uma dificuldade na vivência da disciplina, que foi minorada ao longo de sua construção. 
A dinâmica ocorria da seguinte maneira: a cada aula, era exposta no mural da sala a orientação daquele dia (Fig. 2), e, na área das atividades, eram inseridos o plano de aula e demais materiais que seriam necessários (Fig. 3). Vejamos essa organização:

Figura 2. Orientações de cada aula

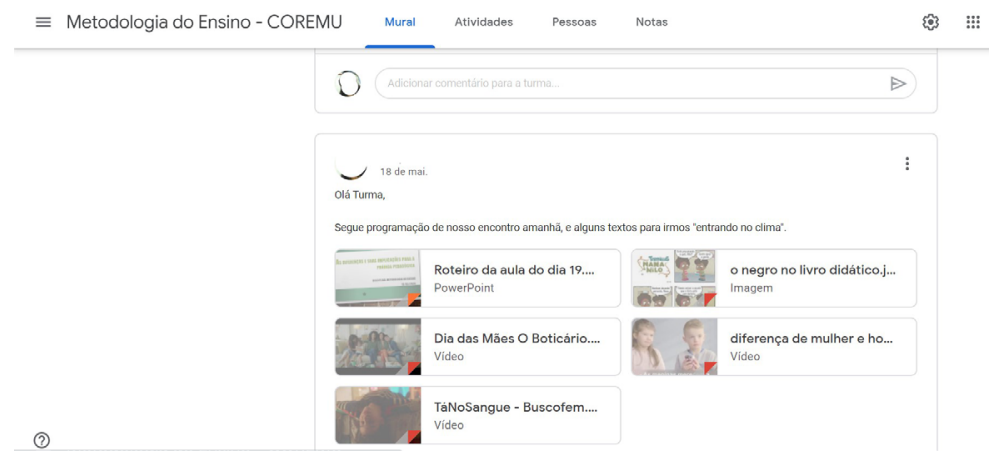

Fonte: Imagem do programa Google Sala de Aula. Produção da autora, 2020.

Figura 3. Inserção dos materiais para cada aula

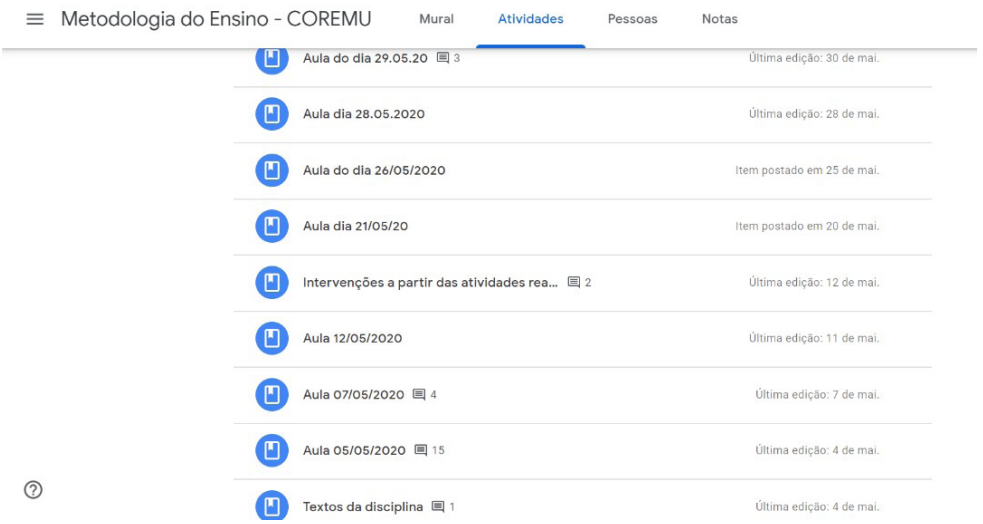

Fonte: Imagem do programa Google Sala de Aula. Produção da autora, 2020.

Para os/as estudantes, essa apresentação do ambiente da sala foi um elemento dificultador, pois, além de terem que, intuitivamente, entender o funcionamento da sala sozinhos, tinham que buscar as orientações em um lugar e os planos e materiais em outro, comprometendo, assim, o acompanhamento adequado da disciplina e, consequentemente, da aprendizagem e vivência de um ensino remoto. 
O/A estudante 28 ilustra bem essa dificuldade:

Fazendo um comentário generalista de como senti a disciplina, senti que a professora era clara, mas o modo de ter que abrir vários arquivos, vários locais com uma série de instruções diferentes era bastante cansativo e dava a sensação de que estava perdendo alguma instrução. Eram muitas etapas e com muitas atividades, ficando muito cansativo diante da rotina.

Além disso, a solicitação da professora para a inserção das atividades realizadas pelos/as estudantes no "mural da sala", seguida das intervenções docentes inseridas para cada uma das atividades, tornou de difícil trânsito esse espaço. Isso é explicitado, também, através do registro feito pelo/a estudante 25: "A construção das instruções no mural da disciplina foi desempenhada de forma conturbada e confusa, dificultando por vezes o desenvolvimento e entendimento do que deveria ser feito na disciplina".

Figura 4. Postagem das atividades discentes no mural

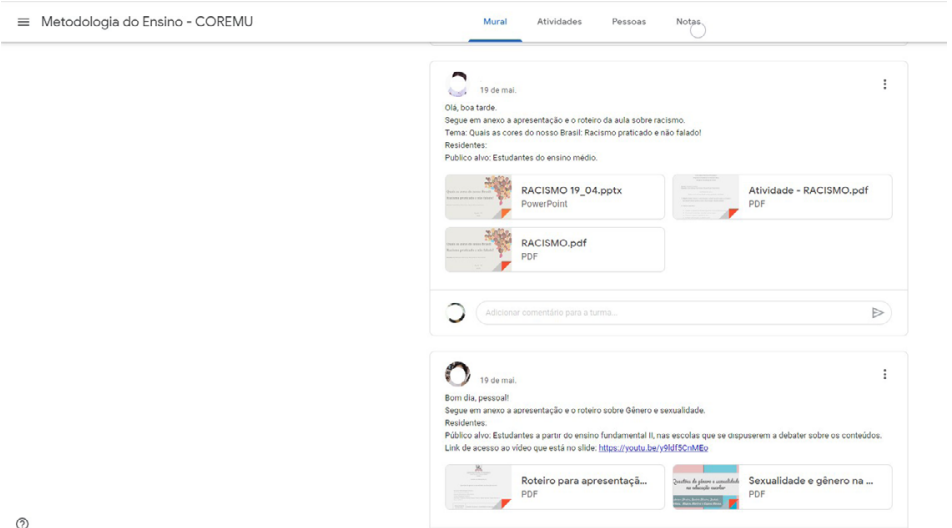

Fonte: Imagem do programa Google Sala de Aula. Produção da autora, 2020.

Figura 5. Orientação individual sobre as atividades no mural da sala

$\equiv$ Metodologia do Ensino - COREMU Mural Atividades Pesssoas Notas

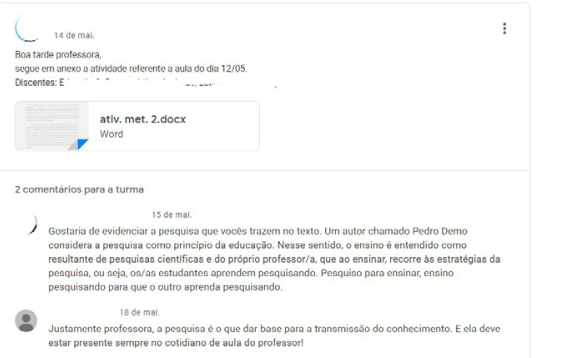

Fonte: Imagem do programa Google Sala de Aula. Produção da autora, 2020. 


\section{(st \\ a dimensão técnica \\ do trabalho docente está \\ vinculada diretamente à necessidade de favorecer \\ a aprendizagem}

Em resumo, a turma percebia que a forma como o aplicativo estava sendo utilizado provocava uma desorganização da disciplina, confundindo e atrapalhando o acompanhamento das orientações e das atividades produzidas pelos/as estudantes, que se dispersavam em um mural repleto de informações, poluído visualmente.

É importante ressaltar que a dimensão técnica do trabalho docente está vinculada diretamente à necessidade de favorecer a aprendizagem. No contexto remoto, essa dimensão se configura como preocupação, em especial por ocorrer o acesso da turma predominantemente de maneira assíncrona, ou seja, sem estar em contato com o/a docente ao mesmo tempo.

A avaliação apresentada pela turma quanto à organização do Google Sala de Aula nos levou a buscar aprender como utilizar adequadamente esse espaço, transformando-o em um ambiente de aprendizagem. A participação no Curso de Formação em GSuite para servidores da universidade, oferecido institucionalmente pela Secretaria de Programas em Educação Aberta e Digital da UFPE (Spread), possibilitou essa aprendizagem - ainda em construção. $\mathrm{E}$, em decorrência desse movimento, temos redesenhado a sala de aula do Google para a turma do segundo semestre de 2020. No mural, agora, só há orientações e comunicações docentes, com a possibilidade de questionamentos discentes:

1 Serviço do Google, agora chamado de Google Workspace, que oferece soluções tecnológicas para empresas, como e-mail personalizado do Gmail, Agenda, Meet, Chat, Drive, Documentos, Planilhas, Apresentações, Formulários, Sites etc. 
Figura 6. Organização do mural para a turma 2020.2

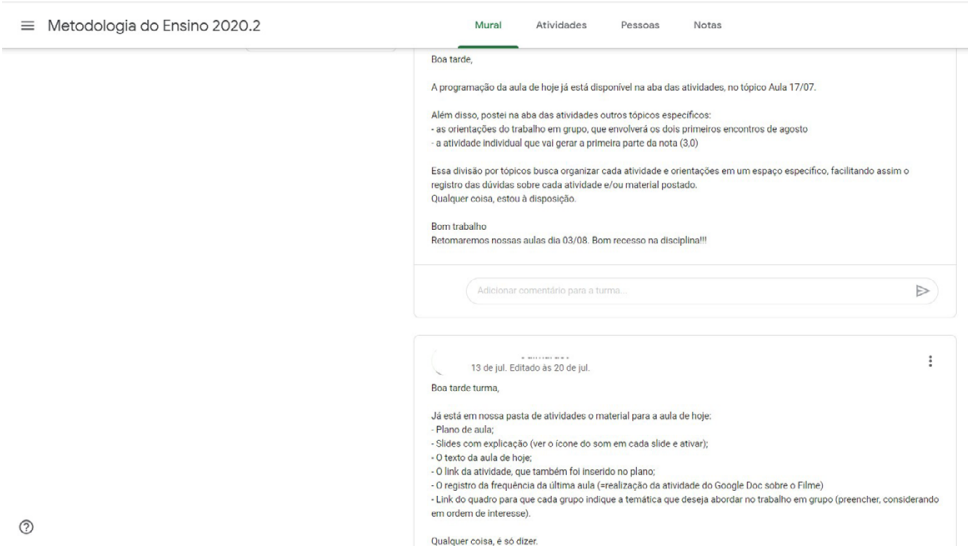

Fonte: Imagem do programa Google Sala de Aula. Produção da autora, 2020.

Planos de aula, slides, textos e atividades estão organizados em um único local, com orientações específicas tanto para o que será feito, como para as postagens e intervenções da professora.

Figura 7. Organização das orientações de aulas e atividades

$\equiv$ Metodologia do Ensino 2020.2
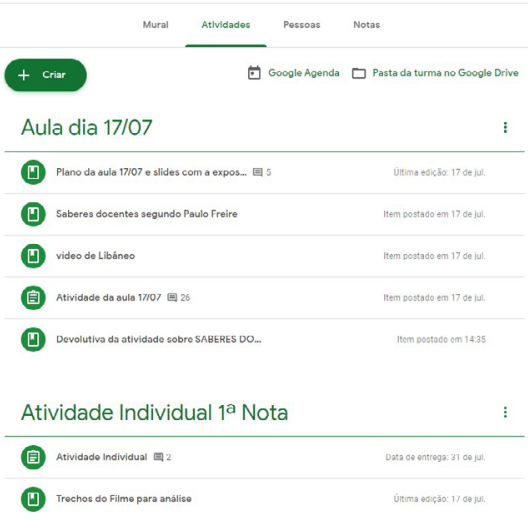

(2)

Trabalho em Grupo - orientações

Fonte: Imagem do programa Google Sala de Aula. Produção da autora, 2020.

Esse novo formato de organização será avaliado ao final da disciplina, com o objetivo de perceber se houve melhoria de acordo com a percepção dos discentes.

Ainda com referência à organização da disciplina, mesmo que não seja de responsabilidade docente, os encontros síncronos via Google Meet também geraram dificuldade, considerando o tipo de equipamento utilizado, a qualidade de acesso à internet e a não 
garantia de que os dias previstos para as aulas nem sempre estavam isentos de plantões, como expressa um/a estudante: "Uma crítica é em relação ao ajuste dos horários das aulas on-line, pois algumas não consegui assistir ao vivo porque nesse horário estava no hospital em serviço" (estudante 34 ).

Outro aspecto a ser destacado com a experiência da aula via Google Meet, relacionado às dificuldades de equipamento e internet, foi a frustração por parte da docente, ainda com a mente presencial, desejava conhecer visualmente a turma, atribuindo os nomes às pessoas, o que não ocorreu. Essa situação leva à necessidade de criar uma nova maneira de conhecer e constituir um grupo, a partir de todas as formas de registro.

Em outras palavras, percebemos que os aspectos vinculados à organização tiveram implicações no desenvolvimento da disciplina, decorrentes tanto do planejamento e acompanhamento docente como do contexto vivido pelos/as estudantes, como as condições pessoais e os trabalhos demandados pelo próprio curso.

\section{A ATUAÇÃO DOCENTE}

O acompanhamento e a dinâmica foram os aspectos destacados pelos/as estudantes como caracterizadores da atuação docente, e que colaboraram com a aprendizagem, mesmo em meio às questões de organização da disciplina abordadas anteriormente.

O acompanhamento se caracterizou por ações de flexibilidade no planejamento das atividades, pelo retorno às produções realizadas e, ainda, pela abertura para o diálogo. É importante ressaltar que, no início da disciplina, o tempo destinado às aulas não estava sendo adequado, em função da finalização das atividades da disciplina anterior e pela falta de garantia de disponibilidade para as aulas nos dias previstos nos cronogramas, considerando-se a distribuição de plantões dos alunos. A resposta a seguir, do/a estudante 1, faz essa sinalização:

\footnotetext{
As propostas da disciplina na primeira quinzena de maio foram confusas, sobrecarregadas e parcialmente inviáveis à nossa rotina teórico-prática na residência. No entanto, após diálogo aberto com a professora, as propostas da segunda quinzena de maio foram muito mais adequadas, levando em consideração atividades curtas e objetivas que tornaram, na minha concepção, a disciplina e os conteúdos mais fáceis de serem compreendidos.
}

Embora essa situação tenha atrapalhado o desenvolvimento inicial das aulas, a atuação docente de acompanhamento influenciou a superação desse momento mais adverso. $\mathrm{O}$ trecho a seguir, 
do/a estudante 8 , apresenta a influência dessas ações para o desenvolvimento das atividades:

Confesso que foram muitas atividades e que houve momentos de sobrecarga com a carga horária prática da residência. Contudo, houve abertura e oportunidade de diálogo com a professora, com flexibilidade para realização e envio de atividades no decorrer da disciplina. Parabenizo ainda pelas alterações metodológicas e uso de metodologias rápidas e ativas, como o quiz rápido.

Percebemos, no trecho, que o acompanhamento e a realização das alterações solicitadas favoreceram, entre outras coisas, a construção do lugar do/a estudante como participante ativo no processo de ensino e aprendizagem, de forma a fazer perceber o diálogo entre essas atividades. Nesse sentido, defendemos que o diálogo entre a professora e a turma é um saber necessário no ensino remoto, assim como é no presencial.

Além disso, o/a estudante 8 também destaca a necessidade de o acompanhamento considerar efetivamente o contexto vivido pelos/as estudantes, pois isso interfere diretamente na participação e no desenvolvimento da disciplina: "Ressalto a dificuldade na tentativa de reunir a presença de todos para a aula virtual, pois são residências diferentes, categorias profissionais diferentes e em regime de plantão, o que dificulta ou impossibilita a participação de alguns".

A dinâmica das aulas foi percebida como ação docente que colaborou com o desenvolvimento e aproveitamento da disciplina. $\mathrm{O}$ uso de ferramentas digitais diferentes foi planejado para a condição assíncrona e para o favorecimento de uma construção mais dinâmica do conhecimento.

Recorremos aos programas da Google (Docs, Apresentações e Forms), com produções individuais e em grupo, incluindo atividades colaborativas, que iam sendo construídas a partir da participação de todos/as. Utilizamos ainda, também gratuitamente, as plataformas Kahoot, que possibilita a realização de jogos, e Mentimeter, que colabora com a organização do conhecimento prévio.

A diversidade de estratégias digitais buscava, assim, colaborar para a realização das atividades, ajudando no aproveitamento do tempo, em que pese a dificuldade que os/as estudantes encontram para equilibrar as demandas geradas pela parte prática da formação (através de plantões e apresentação de seminários aos/ às preceptores/as, entre outras demandas). Acima de $50 \%$ da turma considerou as atividades provocativas $(67,6 \%)$ e significativas para a aprendizagem (73\%). No entanto, houve também o registro significativo de $16,2 \%$ que consideraram as atividades trabalhosas. 
Os recursos e estratégias utilizados também foram percebidos como colaboradores de aprendizagem (54,1\%), enquanto $10,8 \%$ consideraram os recursos e estratégias bons, mas inadequados para a aprendizagem. Esses quantitativos revelam a necessidade de repensar as estratégias, identificando o equilíbrio entre dinamicidade e adequação às necessidades da turma acompanhada.

A atuação docente ocupa espaço significativo no ensino remoto, tal como no presencial. No contexto on-line de ensino e aprendizagem de uma disciplina presencial, precisamos ser "presentes", acessíveis e ter diálogo constante com a turma, em uma condição de escuta permanente.

\section{A APRENDIZAGEM NA DISCIPLINA}

No contexto remoto, destacamos que a vivência era nova tanto para a docente como para os discentes, como afirma o/a estudante 1: "E mesmo que as aulas nesse formato sejam algo novo para todos, creio que foi possível aproveitar da melhor forma os meios tecnológicos disponíveis”. As descobertas e construções, portanto, poderiam representar desafio para ambos.

No entanto, a linguagem da professora e dos textos, predominantes da área da educação, e a predominância de orientações por escrito comprometeram a aprendizagem mais ampla da disciplina, como pode ser ilustrado pela/o estudante 18: "Achei a disciplina, no geral, muito boa, mas sinto que algumas vezes a linguagem da professora não era muito clara, gerando um pouco de confusão mental nos alunos".

O encontro da área de educação com a área de saúde gerou algumas dificuldades para a construção da aprendizagem na disciplina, levando, inclusive, alguns/mas estudantes a considerarem a disciplina interessante, pertinente, mas pouco vinculada ao campo de atuação profissional do grupo. $\mathrm{O}$ gráfico que segue mostra a parcela significativa de estudantes que sentiram essa dificuldade:

Coerência da disciplina com o curso

37 respostas

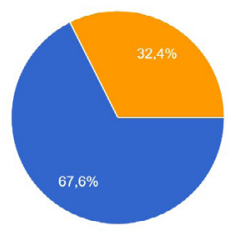

- Adequad:

- Nāo adequada

- Parcialmente adequada

Outro

Fonte: Imagem do programa Google Sala de Aula. Produção da autora, 2020. 
Apesar disso, parte significativa da turma considerou a aprendizagem construída importante para o desenvolvimento profissional, inclusive como possibilidade de atuar através da atividade de ensino. Os registros a seguir informam essa consideração:

Foi de grande valia e de suma importância todo o conteúdo abordado, tornando possivel uma melhor formação como profissionais e como seres humanos. Aprender é um exercício diário, nos foi permitido adquirir mais habilidades e competências (estudante 6)

A disciplina foi extremamente importante, nos mostrou uma visão bem ampla sobre o processo de ensino, estimulando assim o pensamento crítico e mudanças de comportamento e formas de pensar. Porém, senti a necessidade de aproximar a nossa realidade, e um pouco de dificuldade para compreender algumas metodologias (estudante 17).

A disciplina acrescentou muitos pontos positivos, foi uma experiência inovadora e provocativa (estudante 20).

Gostei muito da disciplina, achei muito importante para nos preparar para opções fora da prática hospitalar (estudante 30)

Destacamos, ainda, a partir do registro do/a estudante 26 , a atitude colaborativa no desenvolvimento da disciplina: "Só ressaltar quanto foi enriquecedor a construção dessa disciplina em conjunto a professora”. Essa atitude pode favorecer a construção da aprendizagem de que o processo de ensino e de aprendizagem acontece de maneira dialogada, e não apenas pela escuta docente em relação ao que cada estudante realiza; que o diálogo está presente na própria tessitura da disciplina, construída também a partir de sua vivência, através da posição ativa que o/a estudante assume como sujeito de conhecimento.

\section{UM NOVO DESENHO DA PRÁTICA OU UM DESENHO EM PERMANENTE CONSTRUÇÃO?}

A reflexão sobre a prática reforça a natureza dinâmica do ensino, que tem a relação professor/a-estudante como definidora do caminho construído em busca da aprendizagem, e os saberes da experiência como constituídos nessa relação contextualizada.

Os saberes da experiência profissional aqui partilhados põem em relevo o quanto os diversos saberes, construídos a partir da formação inicial e continuada, são necessários em momentos desafiadores, quando a prática docente é colocada diante de demandas sociais, históricas, que alteram diretamente sua forma de efetivação. 
Considerar o ensino no contexto de pandemia e as implicações diretas desse contexto na prática de docentes e discentes é pensar o lugar desses personagens destituídos de uma aparente zona de conforto, para serem inseridos no que, até então, era desconhecido.

As dificuldades percebidas na organização da disciplina, em especial da forma de orientação para que o/a estudante consiga atuar no seu tempo, com clareza e de forma acompanhada, serviram-nos de indicadores na busca por aprender conhecimentos não dominados e que, para esse formato de ensino, não se reduzem a conhecer; requerem que sejam sabidos de fato.

Pensar em como interagir, sem acompanhar os gestos, sem explicar a explicação, o que comumente se faz presencialmente, recorrendo inclusive a exemplos que melhor contextualizem o conhecimento problematizado, revelou-se para nós como uma dificuldade relevante, em especial na condição da disciplina de Metodologia do Ensino, em um curso na área da saúde. Tornar a relação significativa e o conhecimento aprendido contextualizado e com sentido é nosso desafio.

Para finalizar, consideramos que o ensino remoto, no contexto de pandemia, vai muito além de planejar atividades adaptadas para o mundo on-line, pois requer (re)construir saberes, modificar a lógica de pensar as maneiras de mediar a relação entre estudantes e conhecimento, e, em especial, perceber-se docente como um/a constante aprendente.

\section{Referências}

FREIRE, Paulo. Pedagogia da autonomia: saberes necessários à prática educativa. 36 . ed. São Paulo: Paz e Terra, 2007.

FILATRO, Andrea; CAVALCANTI, Carolina Costa. Metodologias inovativas na educação presencial, a distância e corporativa. São Paulo: Saraiva Educação, 2018.

GAUTHIER, C. et al. Por uma teoria da pedagogia: pesquisas contemporâneas sobre o saber docente. 2. ed. Ijuí: Editora Unijuí, 2006. (Coleção Fronteiras da Educação).

MASETTO, Marcos Tarciso. Aula: ambiente de aprendizagem e de trabalho profissional do docente. In: MASETTO, Marcos Tarciso. Competência pedagógica do professor universitário. São Paulo: Summus, 2003.

MOREIRA, José Antônio Marques; HENRIQUES, Susana; BARROS, Daniela. Transitando de um ensino remoto emergencial para uma educação digital em rede, em tempos de pandemia. Dialogia, São Paulo, n. 34, p. 351-364, jan./abr. 2020. Disponível em: https://periodicos.uninove. br/index.php?journal $=$ dialogia\&page $=$ article\&op=view\&path\% ${ }_{5} \mathrm{~B} \% 5 \mathrm{D}=17123 \& \mathrm{pa}-$ th $\% 5 \mathrm{~B} \% 5 \mathrm{D}=8228$. Acesso em: 30 jun. 2020. PIMENTA, S. G. Formação de professores: identidade e saberes da docência. In: CAMPOS, Edson Nascimento; PIMENTA, Selma Garrido (org.). Saberes pedagógicos e atividade docente. 3. ed. São Paulo: Cortez, 2002. p. 15-34.

TARDIF, Maurice. Saberes profissionais dos professores e conhecimentos universitários: elementos para uma epistemologia da prática profissional dos professores e suas conseqüências em relação à formação para o magistério. Revista Brasileira de Educação, Rio de Janeiro, Associação 
Nacional de Pós-Graduação e de Pesquisa em Educação, n. 13, p. 5-23, jan./abr. 2000.

THERRIEN, J. O saber social da prática docente. Educação e Sociedade, Campinas, n. 46, p. 408-418, abr. 1993.
THERRIEN, J.; LOIOLA, F. A. Experiência e competência no ensino: pistas de reflexões sobre a natureza do saber-ensinar na perspectiva da ergonomia do trabalho docente. Educação e Sociedade, Campinas, n. 74, p. 143-16o, abr. 2001.

一蒲一

Texto submetido em: 29 jul. 2020. Aprovado em: 2 out. 2020.

GUIMARÃES, Orquídea Maria de Souza. Redesenhando a prática docente: uma experiência tecida no contexto de distanciamento social. Estudos Universitários: revista de cultura, Recife, v. 37, n. 1/2, p. 154-17o, dez. 2020. ISSN Edição Digital: 2675-7354. 